\title{
Development Quality Evaluation of Henan Province and Zhengzhou City based on the Coupling and Coordination Relations
}

\author{
Liu Shaoli ${ }^{1 *}$, Zhou Xin ${ }^{2}$ \\ ${ }^{I}$ School of Business, Zhengzhou University of Aeronautics, Zhengzhou, Henan, China \\ ${ }^{2}$ Henan Geology Mineral College, Zhengzhou, Henan, China \\ *Correspondence Author.
}

\begin{abstract}
This paper constructs a quality evaluation indicator system of four systems: economy, society, culture and ecological civilization to measure their coupling relationship and coordination degree indicator, taking Henan province and Zhengzhou city as the research objects, and taking the panel data of 42 specific evaluation indicators from 2000 to 2019 as the evaluation sample. The results show that the biggest contributors to the development quality of economy, culture and ecological civilization of Henan province and Zhengzhou city are the total business volume of posts and telecommunications, the application number of patents, the proportion of investment in environmental pollution control in GDP respectively. During the period of 2000 to 2019, the comprehensive evaluation values of economy, society and culture development quality of Henan province and Zhengzhou city improved constantly, and the change trend were highly consistent, while the changes of that of ecological civilization development quality were far from each other. The coordination degree indicators of the four systems in Henan province and Zhengzhou city were very low, and they are in a state of low disorder at present.
\end{abstract}

Keywords: coordinated development, urban quality evaluation, coupling coordination degree

\section{Introduction}

The report to the 19th CPC National Congress pointed out that China's economy has shifted from a stage of high-speed growth to a stage of high-quality development. High-quality development is a development model that can better meet the people's ever-growing needs for a better life, that embodies the new development philosophy. The concept of coordinated development in the new development philosophy requires that we properly handle the major relations in development. We should not only promote coordinated development among regions, but also coordinate and balance the development of various undertakings, such as the economy, society, culture and ecology. Therefore, this paper considers that high-quality development is not merely reflected in the high quality of a certain field, the high quality of all social fields, but also reflected in the internal coordination of all social fields. Only when various undertakings coordinate and promote each other, can the whole society improve and high-quality development be truly realized.

Henan Province is located in the middle China and lower reaches of the Yellow River, extending from north to south and connecting the east to the west. Henan Province is one of the main birthplaces of the Chinese nation and civilization, and an important economic province in China. In 2019, its GDP continued to rank the 5th in China and was the first in the central and western regions. In 2016, the provincial capital Zhengzhou was entitled as a national central city. As a leader in Henan Province and an important city in the Yellow River Basin, it has a driving effect

ISSN: 0010-8189

(C) CONVERTER 2020

www.converter-magazine.info 
on the other cities and surrounding areas in Henan Province, and also has superior geographical advantages and excellent conditions. With the establishment of Zhengzhou Commodity Exchange, Zhengzhou Air Port Zone and China (Henan) Pilot Free Trade Zone, Henan Province will take these opportunities to achieve higher level and higher quality development.

Due to discrepant geographical location, resource endowment, historical origin and development orientation in different regions, Henan Province have a problem of unbalanced and uncoordinated regional development. However, if Henan Province and Zhengzhou City are regarded as independent whole, whether the internal fields in them such as economy, society, culture and ecological construction have achieved coordinated development? Which aspects have contributed the most to the coordinated development? And what specific indicators restrict the coordinated development?

Taking the High-quality development of urban and even area for the target, this paper evaluated the comprehensive development quality level of Henan province and Zhengzhou city from the perspective of the coordinated development, and further excavated their disharmony and bottlenecks in the course of High-quality development. These ways can fill "short board", and make Henan province and Zhengzhou city better practice High-quality development strategy, Central Plains Rise Strategy, Five in One general layout.

\section{Literature Review}

By the end of 2019, the urbanization rate of China's permanent resident population was 60.6 percent, and that of registered population was 44.38 percent [1]. Although these figures are still lower than the average level of 80 percent in developed countries, they are also an important result of sustained and sound development in economy and society. With the expansion of urban scale and the increase of urban population, urban management and urban development quality evaluation have become the focus of academic research. As early as 2009, Bao Yuehua [2] studied the connotation and measurement of urban development quality from the evolution of concept of quality. And many subsequent scholars began to pay attention to this issue gradually, and adopted a comprehensive indicator system to evaluate the urban development quality step by step [3-5].

The key to evaluate the urban development quality is to establish a scientific comprehensive evaluation indicator system. The United Nations Centre for Human Settlements has compiled City Development indicator and Urban Indicators Guidelines, and the evaluation criteria of foreign literature are basically among these indicators. The common evaluation indicators in domestic literature can be roughly divided into four categories: First, the indicator system is based on urban modernization and urban-rural integration, which measures from the aspects of urban development quality and regional development quality respectively [4, 6-7]; Second, the indicator system is based on material civilization, spiritual civilization and ecological civilization [8-9]; Third, the indicator system is based on residents' life quality, and emphasizes the role of cities in satisfying people's needs and realizing their values [10-11]; Fourth, the indicator system is constructed from the perspective of multiple subsystems such as economy, society, life, resources, environment and infrastructure within the urban system [12-13]. According to the core contents of the research, it can be divided into several research topics: economic development and development mode [14-16], urban and urban-rural integrated development [17-21], industrial structure and industrial agglomeration development [22-23], environmental protection and ecosystem evaluation [24-28]. Research on urban development quality basically adopts multi-objective decision-making methods, including factor analysis method [9, 29], principal component analysis method [10,30], entropy weight method [31-32], cluster analysis method [12,33] and multi-objective linear weighting method [34].

The urban development quality evaluation usually focuses on the Yangtze River Basin urban agglomeration, the Pearl River Delta urban agglomeration and the Beijing-Tianjin-Hebei urban agglomeration, and rarely involves the 
Central Plains urban agglomeration and the Yellow River basin cities. However, the Central Plains urban agglomeration with Henan province as the main body develops rapidly and becomes the fourth growth pole of China's economic development, so it is necessary to have a thorough understanding of its development status. In addition, the development quality evaluation needs objective and comprehensive evaluation indicators and methods, while previous literature often focus on a certain aspect with different purposes, resulting in strong subjectivity and great differences among evaluation indicators.

Under the advocacy of High-quality development, this paper takes Henan province and the provincial capital of Zhengzhou city as the research objects, and evaluates the coupling and coordination degree between their four subsystems as well as their development and change trend during the period of 2000-2019. To evaluate the coupling and coordination degree, the coupling coordination degree model involved economic development quality, social development quality, cultural quality and the ecological development quality is set up from the perspective of harmonious development and the system concept.

\section{Model Setting and Data Description}

\subsection{Model setting}

Based on the practice of other scholars in the study of urban agglomeration and related issues of urban development quality, this study establishes the evaluation indicator system of coordinated development quality from the perspective of harmonious development and the system concept. A relatively objective weighting method-entropy weight method is adopted to determine the indicator weights. The weight values and the final comprehensive evaluation values of the system are calculated on the basis of the panel data of economy, society, culture and ecology of Henan province and Zhengzhou city. Therefore, the comprehensive development quality and evolution process of the whole province and the provincial capital city can be obtained, and the future development direction and specific reform measures of the Yellow River basin can be grasped. The specific model is set as follows:

(1) The $x_{i j}$ represents the data of indicator $\mathrm{j}$ in year $\mathrm{i}(\mathrm{i}=1,2 \ldots, \mathrm{n} ; \mathrm{j}=1,2, \ldots, \mathrm{m})$

(2) The units of measurement of each indicator are not uniform, and it is necessary to standardize each indicator for the sake of eliminating the evaluation error caused by dimension. The standardized formula is as follows, and $\mathrm{x}_{\mathrm{ij}}{ }_{\mathrm{ij}}$ is standardization value:

$$
x_{i j}^{*}=\left(x_{i j}-x_{\min }\right) /\left(x_{\max }-x_{\min }\right)
$$

Calculate the proportion $\mathrm{p}_{\mathrm{ij}}$, and it's the proportion of $\mathrm{x}_{\mathrm{ij}}$ under the indicator $\mathrm{j}$ :

$$
p_{i j}=x_{i j}^{*} / \sum_{i=1}^{n} x_{i j}
$$

Calculate the entropy value of the $\mathrm{j}$ indicator:

$$
e_{j}=-k \sum_{i=1}^{n} p_{i j} \ln \left(p_{i j}\right)
$$

Calculate the weights of each indicator in the four evaluation systems:

$$
\lambda_{\mathrm{j}}=\left(1-e_{j}\right) /\left(m-\sum_{j=1}^{m} e_{j}\right)
$$

ISSN: 0010-8189 
Calculate the comprehensive evaluation values of development quality of the four evaluation systems in the measurement year:

$$
V_{\mathrm{i}}=\sum_{j=1}^{\mathrm{m}} \lambda_{j} x^{*}
$$

Establish the coupling degree model to calculate the coupling relationship and synergistic effect of the four evaluation systems:

$$
C=4 *\left(V_{1} * V_{2} * V_{3} * V_{4}\right)^{1 / 4} /\left(V_{1}+V_{2}+V_{3}+V_{4}\right)
$$

In this formula, $\mathrm{C} \subset[0,1]$. The $\mathrm{C}$ is closer to 1 , the better the coupling relationship and synergistic effect between economic, social, cultural and ecological civilization construction. While the $\mathrm{C}$ approaches to 0 , the less interaction exists between the four evaluation systems.

Coupling coordination degree model. Based on the coupling degree model, the concept of coordinated development is introduced to further calculate the coordinated development degree of the four evaluation systems:

$$
\begin{gathered}
D=\sqrt{C^{*} T} \\
T=\alpha V_{1}+\beta V_{2}+\lambda V_{3}+\sigma V_{4}, \text { and } \alpha=\beta=\lambda=\sigma=0.25
\end{gathered}
$$

Grade division of coupling coordination degree. Referring to the previous research results [35-36], this paper divides the coupling coordination degree into ten continuous and orderly intervals, and assigns them ten corresponding coordination levels (Table 1).

Table 1 The coupling coordination degree interval and grade division

\begin{tabular}{|c|c|c|c|}
\hline $\begin{array}{c}\text { Coupling coordination } \\
\text { degree interval }\end{array}$ & Coordination grade & $\begin{array}{c}\text { Coupling coordination } \\
\text { degree interval }\end{array}$ & Coordination grade \\
\hline $0.0000 \sim 0.0999$ & Extreme disorder & $0.5000 \sim 0.5999$ & Slight coordination \\
\hline $0.1000 \sim 0.1999$ & High disorder & $0.6000 \sim 0.6999$ & Low coordination \\
\hline $0.2000 \sim 0.2999$ & Moderate disorder & $0.7000 \sim 0.7999$ & Moderate coordination \\
\hline $0.3000 \sim 0.3999$ & Low disorder & $0.8000 \sim 0.8999$ & High coordination \\
\hline $0.4000 \sim 0.4999$ & Slight disorder & $0.9000 \sim 1.0000$ & Extreme coordination \\
\hline
\end{tabular}

\subsection{Indicator description and data source}

The evaluation indicator system of coordinated development quality in this paper (Table 2) includes four evaluation subsystems: economic development quality V1, social development quality V2, cultural development quality V3, and ecological civilization development quality V4. Each subsystem covers 13 (V11-V113), 12 (V21-V212), 10 (V31-V310), and 7 (V41-V47) specific evaluation indicators. These 42 specific evaluation indicators basically cover the important fields involved in economy, society, culture and ecological civilization. The data used in this paper covers the period from 2000 to 2019, and includes the quality datasets of economic development, social development, cultural development and ecological civilization development. All of them are from Henan Statistical Yearbook (2001-2020), Zhengzhou Statistical Yearbook (2001-2020), Henan Statistical Bulletin of National Economic and Social Development (2000-2019), Zhengzhou Statistical Bulletin of National Economic and Social Development (2000-2019) and other official statistical data.

Due to the adjustment of relevant policies, the statistical caliber of the indicators of per capita disposable income of

ISSN: 0010-8189 
residents, total volume of goods transportation, total volume of post and telecommunications services, per capita fiscal income, the number of people insured by basic endowment insurance and the number of people insured by basic medical insurance in Henan province and Zhengzhou city had some slight changes. In addition, in consideration of the availability of data, this paper made slight adjustments to the individual evaluation indicators of Zhengzhou. The number of R\&D personnel, R\&D expenditure, and energy consumption per 10,000 yuan of GDP respectively adopted the $R \& D$ personnel of industrial enterprises, $R \& D$ expenditure and energy consumption standards of industrial enterprises above designated size. The number of criminal cases registered in Zhengzhou was calculated according to the population ratio of Zhengzhou and Henan province, and the proportion of the added value of culture and related industries in GDP of Zhengzhou adopted the data of Henan province. This paper mainly studies the development quality and coordination degree of various undertakings in Henan province and Zhengzhou city, and the data is standardized and logarithmic. These practices can reduce the risks of inaccurate measurement results caused by inconsistent statistical caliber of relevant indicators and data substitution.

Table 2 The evaluation indicator system of coordinated development quality

\begin{tabular}{|c|c|c|c|}
\hline $\begin{array}{l}\text { Evaluation } \\
\text { System }\end{array}$ & Evaluation Indicator & Weight/Henan & Weight/Zhengzhou \\
\hline \multirow{13}{*}{$\begin{array}{c}\text { Economic } \\
\text { Development } \\
\text { Quality System } \\
\text { V1 }\end{array}$} & V11 per capita GDP/yuan & 0.06968 & 0.06676 \\
\hline & V12 per capita disposal income of residents/yuan & 0.06664 & 0.07224 \\
\hline & V13 per capita fixed asset investment/yuan & 0.08933 & 0.07717 \\
\hline & V14 per capita retail sales of consumer goods/yuan & 0.08073 & 0.06957 \\
\hline & V15 contribution rate of the tertiary industry $/ \%$ & 0.06109 & 0.07799 \\
\hline & V16 proportion of total imports and exports in GDP/\% & 0.05533 & 0.10394 \\
\hline & $\begin{array}{l}\text { V17 total volume of goods transportation/ten thousand } \\
\text { ton }\end{array}$ & 0.06748 & 0.03366 \\
\hline & $\begin{array}{l}\text { V18 year-end deposit balance of various financial } \\
\text { institutions/ hundred million yuan }\end{array}$ & 0.08326 & 0.07929 \\
\hline & V19 civil car ownership at year-end/ten thousand & 0.09188 & 0.09287 \\
\hline & $\begin{array}{l}\text { V110 total volume of post and telecommunications } \\
\text { services/ hundred million yuan }\end{array}$ & 0.11972 & 0.12326 \\
\hline & V111 per capita fiscal income/yuan & 0.07601 & 0.07456 \\
\hline & V112 total social employment/ten thousand & 0.0753 & 0.05775 \\
\hline & V113 average wage of worker/yuan & 0.06354 & 0.07094 \\
\hline \multirow{4}{*}{$\begin{array}{c}\text { Social } \\
\text { Development } \\
\text { Quality System } \\
\text { V2 }\end{array}$} & V21 natural growth rate of population/\%o & 0.03625 & 0.05946 \\
\hline & V22 registered urban unemployment rate/\% & 0.03099 & 0.04806 \\
\hline & V23 urbanization rate $/ \%$ & 0.05583 & 0.07869 \\
\hline & $\begin{array}{l}\text { V24 number of people insured by basic endowment } \\
\text { insurance/ten thousand }\end{array}$ & 0.16199 & 0.09682 \\
\hline
\end{tabular}




\begin{tabular}{|c|c|c|c|}
\hline & $\begin{array}{l}\text { V25 number of people insured by basic medical } \\
\text { insurance/ten thousand }\end{array}$ & 0.16988 & 0.09947 \\
\hline & $\begin{array}{l}\text { V26 minimum subsistence allowance number/ten } \\
\text { thousand }\end{array}$ & 0.06082 & 0.05554 \\
\hline & V27 length of urban $\mathrm{road} / \mathrm{km}$ & 0.0589 & 0.07126 \\
\hline & V28 commercial housing sales area/ten thousand $\mathrm{m}^{2}$ & 0.10095 & 0.11244 \\
\hline & $\begin{array}{l}\text { V29 per capita income gap between urban and rural } \\
\text { residents /yuan }\end{array}$ & 0.06316 & 0.07915 \\
\hline & V210 number of health technicians/ten thousand & 0.11226 & 0.14227 \\
\hline & V211 health facility beds per 10,000 people/piece & 0.11706 & 0.11523 \\
\hline & V212 number of criminal cases registered/piece & 0.0319 & 0.04161 \\
\hline & V31 education expenditure per student/yuan & 0.1195 & 0.13344 \\
\hline & $\begin{array}{l}\text { V32 number of students enrolled in institutions of } \\
\text { higher learning per } 10,000 \text { people/person }\end{array}$ & 0.05514 & 0.04313 \\
\hline & $\begin{array}{l}\text { V33 number of full-time teachers in schools of all } \\
\text { types and levels per } 10,000 \text { people/person }\end{array}$ & 0.02714 & 0.05145 \\
\hline Darturar & V34 total tourism revenue/hundred million yuan & 0.1448 & 0.12323 \\
\hline Deveropinem & V35 R\&D expenditure/hundred million yuan & 0.13827 & 0.12718 \\
\hline Q & V36 R\&D personnel of full-time equivalent/person & 0.11011 & 0.1037 \\
\hline & V37 number of patent applications/piece & 0.17889 & 0.19655 \\
\hline & $\begin{array}{l}\text { V38 proportion of the added value of culture and } \\
\text { related industries in GDP/\% }\end{array}$ & 0.12233 & 0.12094 \\
\hline & V39 number of public library institutions/piece & 0.0691 & 0.10036 \\
\hline & V310 television broadcasting coverage rate/\% & 0.03471 & 0 \\
\hline & V41 per capita park green area $/ \mathrm{m}^{2}$ & 0.09529 & 0.1856 \\
\hline & $\begin{array}{l}\text { V42 proportion of investment in environmental } \\
\text { pollution control in GDP/\% }\end{array}$ & 0.20734 & 0.25307 \\
\hline Civilization & $\begin{array}{l}\text { V43 energy consumption per } 10,000 \text { yuan of GDP } / \mathrm{kg} \\
\text { of standard coal }\end{array}$ & 0.20354 & 0.19778 \\
\hline Coveropit & V44 treatment rate of domestic sewage/\% & 0.14714 & 0.04971 \\
\hline V4 & V45 household garbage harmless disposal rate/\% & 0.1078 & 0.13502 \\
\hline & $\begin{array}{l}\text { V46 comprehensive utilization rate of general } \\
\text { industrial solid waste/\% }\end{array}$ & 0.07341 & 0.09518 \\
\hline & V47 industrial emission/hundred million $\mathrm{m}^{3}$ & 0.16547 & 0.08364 \\
\hline
\end{tabular}

\section{Results}

\subsection{Indicator weight}

The weight values during 2000-2019 of the 42 specific evaluation indicators used in this paper are also shown in Table 2, and they indicate the contribution of each indicator in each development quality system. For Henan province, the indicators V110 and V16 are the largest and smallest weight in the economic development quality

ISSN: 0010-8189 
system respectively; V25 and V22 are the largest and smallest weight in the social development quality system respectively; V37 and V33 are the largest and smallest weight in the cultural development quality system respectively; V42 and V46 are the largest and smallest weight in the ecological civilization development quality system respectively. For Zhengzhou city, the indicators V110 and V17 are the largest and smallest weight in the economic development quality system respectively; V210 and V212 are the largest and smallest weight in the social development quality system respectively; V37 and V310 are the largest and smallest weight in the cultural development quality system respectively; V42 and V44 are the largest and smallest weight in the ecological civilization development quality system respectively. The television broadcasting coverage rate in Zhengzhou city has been maintained at $100 \%$ during the evaluation period, so its weight value is 0 .

\subsection{Comprehensive evaluation value of Henan province}

Since the beginning of the 21 st century, the comprehensive evaluation values of the development quality in economy, society, culture and ecological civilization system of Henan province have been increasing year by year. Among them, the comprehensive evaluation values of economy, society and culture show a high consistency in the trend of increase, with a fast growth. In 2019, the comprehensive evaluation values of these three systems all reached more than 0.12 . On the other hand, the comprehensive evaluation value of ecological civilization system rises slowly, showing an inconsistent trend with that of other three evaluation systems. In 2019, it is less than 0.07 , only increased by 0.04 compared to 2000 .

Table 3 Comprehensive evaluation value and coupling coordination degree of development quality in Henan province from 2000 to 2019

\begin{tabular}{|c|c|c|c|c|c|c|}
\hline Year & V1 & V2 & V3 & V4 & C & D \\
\hline 2000 & 0.00161 & 0.00607 & 0.00027 & 0.02788 & 0.3274 & 0.05415 \\
\hline 2001 & 0.00551 & 0.01646 & 0.00266 & 0.02775 & 0.69062 & 0.09509 \\
\hline 2002 & 0.00632 & 0.00902 & 0.00563 & 0.02927 & 0.78396 & 0.09923 \\
\hline 2003 & 0.00792 & 0.00997 & 0.00762 & 0.03345 & 0.80809 & 0.10914 \\
\hline 2004 & 0.00935 & 0.01136 & 0.00981 & 0.03406 & 0.85018 & 0.11715 \\
\hline 2005 & 0.01432 & 0.01443 & 0.01402 & 0.04545 & 0.8637 & 0.13801 \\
\hline 2006 & 0.01858 & 0.01967 & 0.01817 & 0.04437 & 0.92465 & 0.15265 \\
\hline 2007 & 0.02497 & 0.02317 & 0.02217 & 0.04627 & 0.95231 & 0.1666 \\
\hline 2008 & 0.03128 & 0.02534 & 0.02697 & 0.04689 & 0.96999 & 0.17787 \\
\hline 2009 & 0.03758 & 0.03492 & 0.03354 & 0.05051 & 0.98663 & 0.19651 \\
\hline 2010 & 0.03859 & 0.03999 & 0.03884 & 0.04881 & 0.99519 & 0.20337 \\
\hline 2011 & 0.05051 & 0.05414 & 0.04977 & 0.05744 & 0.99835 & 0.22995 \\
\hline 2012 & 0.05947 & 0.06293 & 0.06168 & 0.05417 & 0.99837 & 0.24385 \\
\hline
\end{tabular}




\begin{tabular}{|l|c|c|c|c|c|c|}
\hline 2013 & 0.06538 & 0.06984 & 0.07219 & 0.06194 & 0.99826 & 0.25927 \\
\hline 2014 & 0.07289 & 0.07466 & 0.07988 & 0.06366 & 0.99666 & 0.26931 \\
\hline 2015 & 0.08677 & 0.07941 & 0.0872 & 0.06447 & 0.99282 & 0.28088 \\
\hline 2016 & 0.09554 & 0.0859 & 0.09836 & 0.06213 & 0.98446 & 0.2901 \\
\hline 2017 & 0.1052 & 0.11862 & 0.11117 & 0.06441 & 0.97372 & 0.31181 \\
\hline 2018 & 0.12509 & 0.11968 & 0.12683 & 0.06772 & 0.96956 & 0.32632 \\
\hline 2019 & 0.14312 & 0.12442 & 0.13322 & 0.06935 & 0.96364 & 0.33653 \\
\hline
\end{tabular}

\subsection{Comprehensive evaluation value of Zhengzhou city}

The comprehensive evaluation values of the development quality in economy, society, culture system of Zhengzhou city also increased year by year from 2000 to 2019, and showed a high consistency in the increasing trend, with a fast growth. However, their comprehensive evaluation values produced a large difference in 2019. The comprehensive evaluation value of the development quality in ecological civilization system did not show a specific trend during this period. It decreased from 2000 to 2003, increased in 2003, then began to decline in 2008, and slowly increased in 2012. On the whole, the comprehensive evaluation value of the ecological civilization system in Zhengzhou in 2019 is basically the same as that in 2000.

Table 4 Comprehensive evaluation value and coupling coordination degree of development quality in Zhengzhou city from 2000 to 2019

\begin{tabular}{|c|c|c|c|c|c|c|}
\hline Year & V1 & V2 & V3 & V4 & $\mathrm{C}$ & $\mathrm{D}$ \\
\hline 2000 & 0.00582 & 0.00565 & 0.00045 & 0.06028 & 0.30316 & 0.07397 \\
\hline 2001 & 0.0074 & 0.01101 & 0.00153 & 0.04701 & 0.52238 & 0.0935 \\
\hline 2002 & 0.01 & 0.0113 & 0.00328 & 0.04678 & 0.64327 & 0.10713 \\
\hline 2003 & 0.01114 & 0.0137 & 0.00667 & 0.04213 & 0.78163 & 0.11996 \\
\hline 2004 & 0.01278 & 0.01701 & 0.00984 & 0.06964 & 0.71915 & 0.14016 \\
\hline 2005 & 0.01373 & 0.02105 & 0.01226 & 0.07263 & 0.75289 & 0.15008 \\
\hline 2006 & 0.0183 & 0.02721 & 0.01893 & 0.07607 & 0.82842 & 0.17059 \\
\hline 2007 & 0.02436 & 0.03282 & 0.0223 & 0.05248 & 0.94274 & 0.17635 \\
\hline 2008 & 0.02405 & 0.03516 & 0.0321 & 0.05999 & 0.9444 & 0.1890 \\
\hline 2009 & 0.02996 & 0.04163 & 0.03582 & 0.04088 & 0.99161 & 0.19173 \\
\hline 2010 & 0.03694 & 0.04526 & 0.03768 & 0.03794 & 0.99656 & 0.1983 \\
\hline 2011 & 0.04394 & 0.04979 & 0.04779 & 0.03577 & 0.99218 & 0.2097 \\
\hline 2012 & 0.05878 & 0.0573 & 0.0602 & 0.03216 & 0.96972 & 0.2248 \\
\hline 2013 & 0.06754 & 0.06701 & 0.06995 & 0.03524 & 0.96427 & 0.2404 \\
\hline 2014 & 0.07482 & 0.0715 & 0.07705 & 0.04002 & 0.96784 & 0.25245 \\
\hline 2015 & 0.0862 & 0.07771 & 0.0856 & 0.03875 & 0.9527 & 0.26202 \\
\hline 2016 & 0.09593 & 0.09156 & 0.09742 & 0.05128 & 0.96837 & 0.28529 \\
\hline 2017 & 0.10575 & 0.10067 & 0.11094 & 0.05236 & 0.95942 & 0.29779 \\
\hline 2018 & 0.12822 & 0.11013 & 0.1346 & 0.05225 & 0.9391 & 0.31595 \\
\hline 2019 & 0.14436 & 0.11251 & 0.13559 & 0.05637 & 0.9407 & 0.32489 \\
\hline
\end{tabular}




\subsection{Coordinated development trend of four systems}

The coupling degree indexes of economy, society, culture and ecological civilization evaluation systems in Henan province and Zhengzhou city have been kept above 0.9 after 2007 respectively. The coupling relationship and synergistic effect of various fields within Henan province are slightly stronger than that of Zhengzhou city, and the degree of interaction and mutual influence is also deeper. On the other hand, the broken lines of the coupling coordination degree index of the four evaluation systems in Henan province and Zhengzhou city almost coincide, showing a high degree of consistency, which is consistent with the coordinated development grades (Table 5).

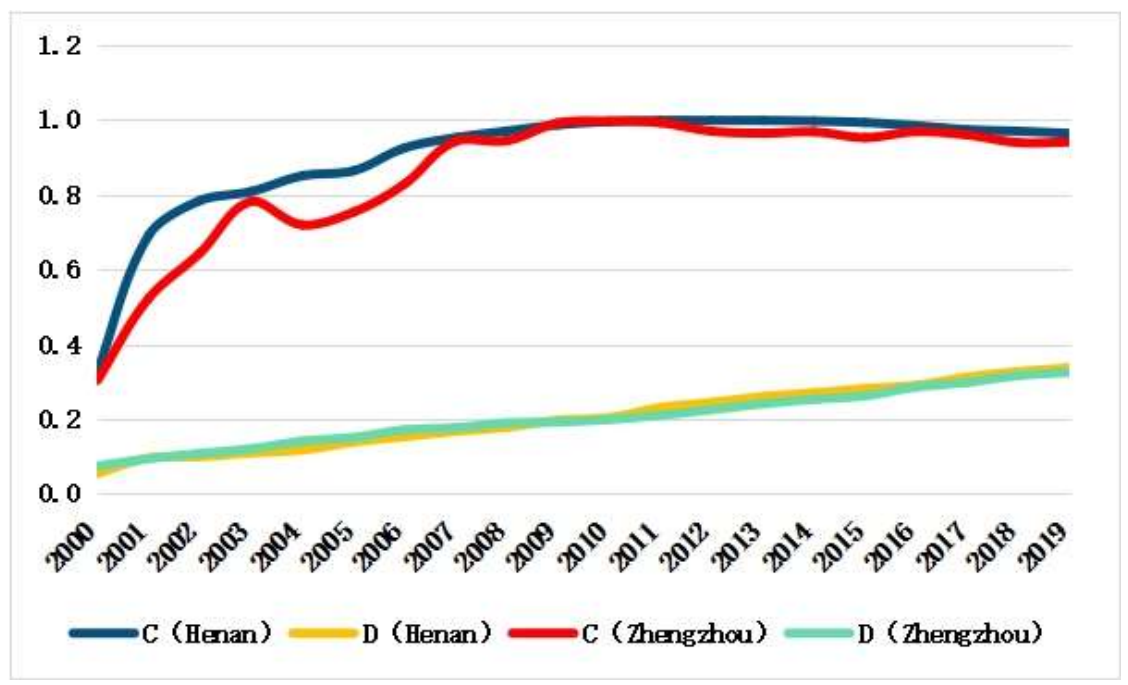

Fig 1: The coordinated development trends of four evaluation systems in Henan province and Zhengzhou city from 2000 to 2019

The coordination degrees among four evaluation systems within Henan province and Zhengzhou city have improved respectively, from the extreme disorder in the early 21 st century to the low disorder at present, but it is still in a state of disorder. This is obviously different from the concept of coordinated development, which emphasizes on comprehensiveness and integrity. As the provincial capital, Zhengzhou city was given priority to the development of all fields, but the speed and quality is uneven. Therefore, mining the specific indicators of uncoordinated development is the future direction and goal of the city, and they can provide strong impetus to coordinated development and high-quality development.

Table 5 The coordinated development stage of Henan province and Zhengzhou city

\begin{tabular}{|c|c|c|c|}
\hline Stage & Coordination grade/Henan & Stage & Coordination grade/Zhengzhou \\
\hline $2000-2002$ & Extreme disorder & $2000-2001$ & Extreme disorder \\
\hline $2003-2009$ & High disorder & $2002-2010$ & High disorder \\
\hline $2010-2016$ & Moderate disorder & $2011-2017$ & Moderate disorder \\
\hline $2017-2019$ & Low disorder & $2018-2019$ & Low disorder \\
\hline
\end{tabular}

\section{Discussion}

According to the weights of evaluation indicators during 2000-2019, V110, V37 and V42 are the factors that

ISSN: 0010-8189

(C) CONVERTER 2020

www.converter-magazine.info 
contribute the most to the development quality of economy, culture and ecological civilization of Henan province and Zhengzhou city respectively. Accompanied by the increasing prosperity of the global network economy with modern information technology as the core, new consumption and communication ways have greatly promoted total volume of post and telecommunications services. The average growth rates are about 29\% (Henan province) and $26 \%$ (Zhengzhou city), which is much higher than other indicators of the economic development quality system. Henan province is in an important period of strategic opportunities. In order to adapt to the new normal for economic development, Henan must rely on scientific and technological innovation. Therefore, the number of patent applications, R\&D expenditure, education expenditure per student and other indicators are growing quickly. Henan province and Zhengzhou city both attach great importance to the cultivation of autonomous innovation ability of science and technology talents, and invest heavily in related innovation projects and talent projects. Ecological civilization construction was written into the national Five-Year Plan for the first time in 2015 to deal with the grim situation of resource constraints, environmental pollution and ecological degradation. Investment in environmental pollution control is the foundation and guarantee of ecological civilization construction, so this indicator makes a great contribution to the ecological civilization development quality. In addition, under the advocacy and policies of "Energy Conservation and Emission Reduction" and "Action Plan to Protect the Blue Sky", the indicators such as V43 and V47 also significantly reduced. The social development quality evaluation system covers a wide range of contents, and the social service practice level of different regions in Henan varies greatly. Thus the weights of social development quality evaluation indicators of Henan province and Zhengzhou city are uneven, and there are no common indicators of maximum and minimum contribution.
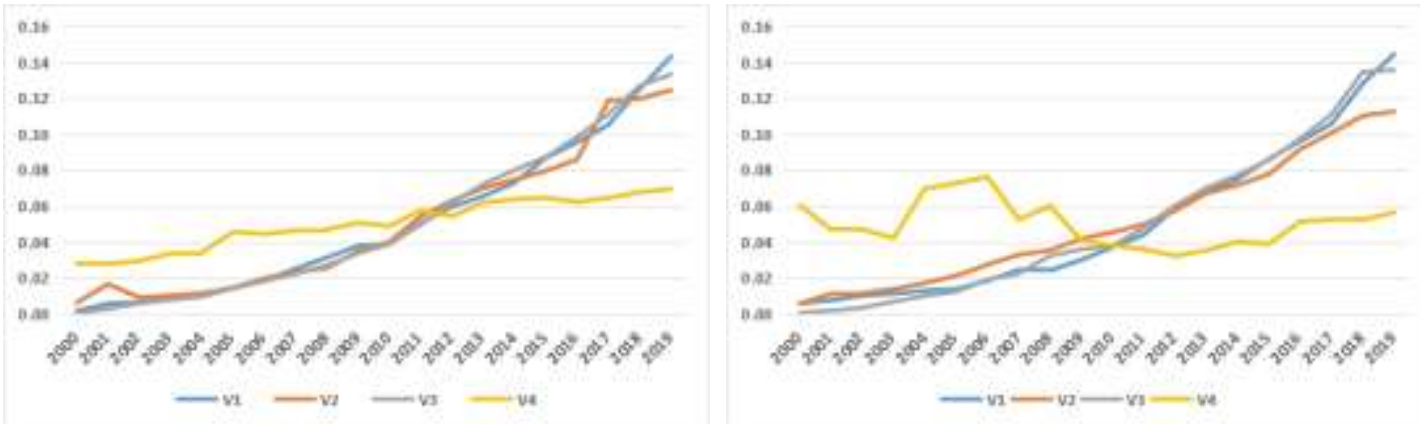

Fig 2: The trend of comprehensive evaluation value of various fields in Henan province (left) and Zhengzhou city

$$
\text { (right) }
$$

During 2000-2019, the change trend of comprehensive evaluation values of economic, social and cultural development quality in Henan province and Zhengzhou city are basically the same, while that of comprehensive evaluation value of ecological civilization development quality is very different during this period. On the whole, the ecological civilization quality in Henan province is improving steadily, but the improvement speed is relatively slow. The ecological civilization quality of Zhengzhou city fluctuates, and the comprehensive evaluation value is lower than the overall level of the province. As a provincial capital city, Zhengzhou has undertaken a large number of responsibilities such as population inflow, economic and industrial development, infrastructure construction, and higher consumption level. Henan province has 17 prefecture-level cities and 1 county-level administrative unit directly under the jurisdiction of the province. By the end of 2019, the Zhengzhou's total population, GDP and civil car ownership are $9.5 \%, 21.4 \%$ and $24 \%$ of the province's, respectively. The Zhengzhou's per capita fixed asset investment and per capita retail sales of consumer goods are 1.8 times and 2.2 times of the province's, respectively. Although Zhengzhou city implemented stricter environmental protection policies than other regions within province in recent years, the inevitable production and living activities still make the ecological civilization construction face severe tests. On the other hand, compared with other comprehensive evaluation values, the evaluation values of ecological civilization development quality in Henan province and Zhengzhou city are both lower. These results are built on the background that China paid attention to economic increment and adopted 
extensive development mode for a long time. The concepts of sustainable development and ecological civilization become increasingly popular. The implementation of strict environmental protection policies such as "Energy Conservation and Emission Reduction", "Action Plan to Protect the Blue Sky" and "Domestic Waste Classification" will also achieve good environmental benefits and improve the ecological civilization development quality.

At present, the four evaluation systems in Henan province and Zhengzhou city are developing continuously, improving their quality and have a relatively high coupling degree. However, the development starting point, speed and emphasis of each field are different, and the coordination degrees are very low, and the fields are in a state of disorder. Combined with the development quality evaluation indicator system and the coupling coordination degree model established in this paper, the main reason for the development disorder is the incoordination between the ecological civilization system and the economic, social and cultural systems, which is also reflected in the comprehensive evaluation values of development quality. The ultimate aim of development is to make the residents to obtain sustainable environment and a higher quality of life. So in the future development process, Henan province and Zhengzhou city should not only keep a good development trend in all fields of economic, social and cultural systems, but also pay more attention to the ecological civilization construction, especially the quality evaluation indicators with low weight values.

\section{Conclusion}

In this paper, the evaluation indicator system of coordinated development quality is constructed to evaluate the development quality of Henan province and Zhengzhou city from the perspective of coordinated development in various internal fields. The main research conclusions are as follows:

(1) During 2000-2019, the total volume of post and telecommunications services, the number of patent applications and the proportion of investment in environmental pollution control in GDP are the factors that contribute the most to the development quality of economy, culture and ecological civilization of Henan province and Zhengzhou city respectively.

(2) During 2000-2019, the change trend of the comprehensive evaluation values of economic, social and cultural development quality in Henan province and Zhengzhou city are basically the same, showing a trend of continuous improvement. While the change trend of the comprehensive evaluation value of the ecological civilization development quality during this period is very different.

(3) The coordination degree indexes of economy, society, culture and ecology in Henan province and Zhengzhou are very low, and it is still in a state of low disorder.

The main research shortcomings of this paper are as follows: on the one hand, the indicators in the development quality evaluation system still need to be increased and improved, and the data collection work needs to be continued and careful; On the other hand, in the calculation formulas of the coupling coordination degree model, $\alpha$, $\beta, \lambda$ and $\sigma$ represent the coordinated development parameter $T$ to be estimated among the four systems, which is an empirical value of 0.25 , and fails to accurately distinguish the differences between systems.

In the future, the author and the team will further collect indicators and panel data sets that cover the Central Plains Urban Agglomeration, which includes 30 cities in 5 provinces, and involves economic, social, cultural, ecological civilization development quality. The team strives for establishing database of the Central Plains Urban Agglomeration development quality, to evaluate the development quality of the Central Plains Urban Agglomeration comprehensively and accurately. These practices can grasp the development bottlenecks of the Central Plains Urban Agglomeration, and will promote the comprehensive and high-quality development of the 
Central Plains Urban Agglomeration.

\section{Acknowledgements}

This work was supported by Philosophy and Social Science Program of Henan Province in 2020 (2020CZH011), Philosophy and Social Science Program of Henan Province in 2019 (2019BJJ061), and Humanities and Social Science General Project of Education Department of Henan Province in 2021 (2021-ZDJH-403).

\section{References}

[1] China Economic Net. National Bureau of Statistics: In 2019, China's urbanization rate exceeded 60\%, and the urbanization rate of household registration was $44.38 \%$. http://www.ce.cn/xwzx/gnsz/gdxw/202002/28/t20200228_34360903.shtml. 2020-2-28.

[2] Y.H. Bao, Q. Chen, "The evolution of quality and the quality of urban development". Tongji University Journal Social Science Section, vol. 20, no. 6, pp. 46-52, 2009.

[3] Z.L. Han, T.B. Liu, "Analysis of the characteristics and spatial differences of urbanization quality of cities at prefecture level and above in Chin”a. Geographical Research, vol. 28, no. 6, pp. 1508-1515, 2009.

[4] M.Q. Li, X.B. Lang, "The connotation of urbanization quality and the construction of its evaluation index system". Chinese Soft Science Magazine, no. 12, pp. 182-186, 2010.

[5] C.L. Fang, D.L. Wang, "Comprehensive measures and improvement of Chinese urbanization development quality”. Geographical Research, vol. 30, no. 11, pp. 1931-194, 2011.

[6] Y.M. Ye, “Approach on China's urbanization quality”. Chinese Soft Science Magazine, no. 7, pp. 27-31, 2001.

[7] Y.P. Xiao, Y.L. Yang, Y. Song, “Comprehensive evaluation on urbanization quality and its spatial and temporal characteristics in China”. China Population, Resources and Environment, vol. 28, no. 9, pp. 112-122, 2018.

[8] L. Li, G.X. Zhang, "The city development quality of Beijing-Tianjin-Hebei urban agglomeration". Economic Geography, vol. 35, no. 5, pp. 61-64+8, 2015.

[9] H.B. Deng, X.T. Liu, "The modes and path of improving the development quality of urban agglomeration in the middle reaches of the Yangtze River”. Journal of Central China Normal University (Nat. Sci.), vol. 53, no. 5, pp. 622-630+642, 2019.

[10] D.B. Yan, M.Y. Zhang, H. Zhang, "An empirical study on the urbanization quality in Hebei province". Review of Economic Research, no. 29, pp. 36-42, 2014.

[11] L. Deng, F. Wang, "The evaluation study of urban human settlements development quality under the background of shared development: take Nanjing as an example”. Ecological Economy, vol. 33, no. 10, pp. 205-209, 2017.

[12] Z.M. Zhu, H.S. Yu, "Evaluation of urbanization quality in developed coastal areas of southeast China: take the Yangtze River Delta as an example”. Lanzhou Academic Journal, no. 11, pp. 81-84, 2013.

[13] R. Wang, J.H. Cheng, "Coupling analysis of economy, society, resources and environment in the Yangtze River Delta urban agglomeration from the perspective of high-quality development". Academic Forum, no. 6, pp. 1-7, 2019.

[14] Z.C. Zhang, X.Z. Yang, Y.Z. Yang, "Characteristics and development approaches of central plains urban agglomeration”. Zhengzhou Daily, 2004-07-23(14).

[15] B.L. Xia, L.Q. Lv, "Study on the spatial development and layout in Zhongyuan city cluster". Journal of Zhengzhou Institute of Aeronautical Industry Management, vol. 27, no. 1, pp. 32-36, 2009.

[16] H.Q. Zhang, "Analysis of the economic disparities and their spatio-temporal evolution in Zhongyuan Urban Agglomeration”. Journal of Urban Studies, vol. 39, no. 6, pp. 51-57, 2018.

[17] J.Y. Liu, "Research on economic integration of Central Plains Urban Agglomeration under the background 
of contemporary urbanization”. Kaifeng: Henan University, 2006.

[18] J.T. Yang, J.H. Gao, Y.J. Shi, "Studies on the trend and development of the urbanization of Zhongyuan Urban Agglomeration: A PIL perspective”. China Land Sciences, vol. 28, no. 3, pp. 59-66, 2014.

[19] Z.W. Ding, L.M. Huang, H.Y. Xie, et al. "Economic spatial pattern and its influencing factors of Central Plains Urban Agglomeration at town scale”. Economic Geography, vol. 39, no. 11, pp. 60-68, 2019.

[20] Y. Chen, W.T. Tian, W.B. Ma, et al. "Analysis on spatio-temporal differentiation and influence factors between population urbanization and land urbanization based on ESDA-GWR-A case study of the Central Plains Urban Agglomeration". Chinese Journal of Agricultural Resources and Regional Planning, no. 8, pp. 88-99, 2020.

[21] C.F. Ma, D. Jia, J. Li, W.H. Zhu, “A preliminary study of "urban capability": new thinking on China's new urbanization research". Urban Development Studies, vol. 27, no. 233, pp. 7-11+88, 2020.

[22] L.J. Zhang, Y.C. Qin, J.P. Zhang, Y. Zhang, "The pattern of county's industrial agglomeration based on learning location theory: A case study for Zhongyuan urban agglomerations”. Economic Geography, vol. 31, no. 8, pp. 1301-1307, 2011.

[23] Y.T. Feng, Y.F. Zhang, "An analysis of the evolution features of the economic barycenter and the industrial barycenter of the central henan urban agglomeration”. Journal of Management, vol. 31, no. 6, pp. 10-20, 2018.

[24] X.X. Xu, "City ecosystem evaluation of Zhongyuan city group region". Areal Research and Development, vol. 25, no. 5, pp. 98-102, 2006.

[25] G.Y. Wang, J. Liu, "Coordinating evaluation of water resources environment and economic development based on improved water ecological footprint: A case study of central plains urban agglomeration". Resources and Environment in the Yangtze Basin, vol. 28, no. 1, pp. 80-90, 2019.

[26] Y. Han, M.L. Deng, "Spatio-temporal evolution of eco-efficiency and influencing factors of central plains urban agglomeration”. Acta Ecologica Sinica, vol. 40, no. 14, pp. 4774-4784, 2020.

[27] Z.Z. Zhou, J.L. Wang, "Study on the coupling coordination between urbanization and ecological environment in the Yangtze River Economic Belt". Urban Problems, no. 4, pp. 21-32, 2020.

[28] X.H. Liu, "Study on the influence of urban sprawl on haze pollution”. Urban Problems, no. 4, pp. 90-96, 2020.

[29] Q. Wang, C. Jin, "Quantitative measurement of economic development imbalance among urban agglomerations in China”. The Journal of Quantitative \& Technical Economics, no. 11, pp. 77-94, 2018.

[30] X.Y. Zhan, P.P. Cui, "Estimation and evaluation of China's provincial quality of Economic growth-empirical analysis based on "Five Development Concepts"”. Public Finance Research, no. 8, pp. 39, 40-53, 2016.

[31] N.X. Zuo, Y.P. Bai, J.P. Zuo, “Quality measurement of urbanization in Gansu province”. Resource Development \& Market, vol. 30, no. 10, pp. 1158-1161+1267, 2014.

[32] M. Wei, S.H. Li, "Construction and measurement of the evaluation system of China's economic growth quality under the new normal”. Economist, no. 4, pp. 19-26, 2018.

[33] Y.C. Yang, Y.J. Mu, W. Zhang, "Basic conditions and core strategies of high-quality development in the Yellow River Basin”. Resources Science, vol. 42, no. 3, pp. 409-423, 2020.

[34] Q. Jia, Y.X. Yun, "Measurement of urbanization development quality and analysis of regional dis- parities in Beijing-Tianjin-Hebei metropolitan region". Journal of Arid Land Resources and Environment, vol. 29, no. 3, pp. 8-12, 2015.

[35] P. Yi, S.M. Fang, "Coupling coordination between the socio-economic benefits and eco-environmental benefits of the Songshan Global Geopark”, Resources Science, vol. 36, no. 1, pp. 0206-0216, 2014.

[36] Z.G. Chen, J. Chen, J.H. Du, "Study on coupling coordination development between logistics industry and national economy in China-an empirical analysis based on provincial panel data". China Business and Market, vol. 34, no. 1, pp. 9-20, 2020. 